\title{
Medical costs of smoking in the United States: estimates, their validity, and their implications
}

\author{
Kenneth E Warner, Thomas A Hodgson, Caitlin E Carroll
}

\begin{abstract}
Objective-To compare estimates of the medical costs of smoking in the United States and to consider their relevance to assessing the costs of smoking in developing countries and the net economic burden of smoking.

Data sources-A Medline search through early 1999 using keywords "smoking" and "cost", with review of article reference lists.

Study selection-Peer-reviewed papers examining medical costs in a single year, covering the non-institutionalised American population.
\end{abstract}

Data extraction-Methods underlying study estimates were identified, described, and compared with attributable expenditure methodology in the literature dealing with costs of illness. Differences in methods were associated with implied differences in findings.

Data synthesis-With one exception, the studies find the annual medical costs of smoking to constitute approximately $6-8 \%$ of American personal health expenditures. The exception, a recent study, found much larger attributable expenditures. The lower estimates may reflect the limitation of analysis to costs associated with the principal smoking-related diseases. The higher estimate derives from analysis of smoking-attributable differences in all medical costs. However, the finding from the most recent study, also considering all medical costs, fell in the 6-8\% range.

Conclusions-The medical costs of smoking in the United States equal, and may well exceed, the commonly referenced figure of $6-8 \%$. This literature has direct methodological relevance to developing countries interested in assessing the magnitude of their current cost-ofsmoking burden and their future burdens, with differences in tobacco use histories and the availability of chronic disease treatment affecting countryspecific estimates. The debate over the use of gross or net medical cost estimates is likely to intensify with the proliferation of lawsuits against the tobacco industry to recover expenditures on tobaccoproduced disease.

(Tobacco Control 1999;8:290-300)

Keywords: medical costs; smoking; United States
Introduction

Interest in the medical costs of cigarette smoking derives from the desire to identify the economic burden that smoking imposes on a society. This burden is typically characterised as consisting of these medical costs plus productivity losses attributable to smokingrelated morbidity, disability, and premature mortality. ${ }^{1}$ Invariably large, the economic burden is frequently cited by activists campaigning in support of tobacco control policy measures.

Recently, the medical cost estimates have gained more immediate and specific salience as most of the states in the United States, selected health insurers, and the governments of several countries have sued the tobacco industry to recover smoking-related healthcare expenditures. The first such suits were brought by the American states to recover the costs of smokers dependent on state financing through the Medicaid programme. ${ }^{2}$ Analysts working for the states developed estimates of state-specific costs for use at trial or in settlement discussions. ${ }^{3}$ In the four cases that went to trial (Mississippi, Florida, Texas, and Minnesota), the tobacco industry agreed to pay the states nearly US $\$ 36$ billion over a 25 -year period. ${ }^{4}$ In an attempt to avoid further litigation, featuring these medical expenditure-based suits, the industry developed a wide-reaching national settlement proposal with attorneys representing the states. Legislation needed to bring the agreement to fruition foundered in the United States Congress. ${ }^{4}$ However, in fall 1998 the industry and all of the remaining states reached a more limited agreement, settling the individual states' suits and establishing modest restrictions on the industry's marketing behaviours. ${ }^{5}$

Estimation of the medical costs associated with smoking-produced illness dates back at least two decades. ${ }^{6}$ In this paper, we review the literature on these estimates as they pertain to the medical economy of the United States. We then consider the implications of the findings of this body of analysis, with a particular interest in the implications for other countries.

In the next section, we examine the published literature on the medical costs of smoking in the United States, considering analytical methods and the validity and consistency of resulting findings. In addition to determining whether there is a consensus on the magnitude of the burden, we assess whether, and if so how, similarities or differences in data sources and analytical methods can explain similarities and differences in findings across various studies. We focus exclusively on American analyses for two 
reasons. First, the United States is the country with the largest number of peer-reviewed analyses of this issue. Second, comparison of findings across studies requires limiting the analysis to a single country, since, as is discussed in the following section of the paper, differences in smoking histories, population demographics, stage of economic development, and medical care systems may produce differences in the incidence of smoking-produced diseases and in expenditures on smoking-related illnesses.

In the following section, we consider the relevance of the American analyses, methodologically and substantively, to understanding the medical cost burden of smoking in other countries. Of special interest is the case of the developing country that is only now becoming aware that smoking is consuming healthcare resources: how large is that burden likely to be today? How will it change in the future?

The fourth section examines the meaning of the cost-of-smoking estimates in the context of the controversial issue of whether one should calculate the net or the gross costs of smokingproduced illness. Most of the literature reviewed in this paper evaluates the gross costs - all of the expenditures associated with treating diseases attributable to smoking. Other authors have observed, however, that because smokers die younger than nonsmokers on average, smoking should be credited with medical cost "savings." In other words, according to these authors an evaluation of the medical costs of smoking should examine those costs net of the reductions in other, later healthcare costs that many smokers do not live to incur. Which perspective is right? More appropriate is the question, under what circumstances is each perspective correct?

The final section of the paper summarises our principal findings and conclusions.

\section{Estimates of the medical costs of smoking in the United States}

METHODS

Using a Medline search and the reference lists from the identified articles, we generated a list of all published studies on the medical costs of smoking in the United States through early 1999 , as well as several studies not published in the peer-reviewed literature, such as government reports. We restricted our review to papers that were directly on theme. As such, we excluded a number of studies that, although relating to the medical costs of smoking, either examined costs in a manner not consistent with our interest in medical costs during a single year, ${ }^{7-10}$ considered only a subset of smokers, ${ }^{11}$ or used data from another country to develop an American estimate. ${ }^{12}$ We further restricted the list to papers published in peer-reviewed scholarly journals, with one important exception: we included a staff report by the former Congressional Office of Technology Assessment (OTA) on the costs of smoking in $1985 .{ }^{13}$ This analysis is frequently cited in the literature and was subjected to the scrutiny of a distinguished advisory panel and a thorough external peer review. An update and revision of the OTA study, prepared by staff for Congressional testimony in $1993,{ }^{14}$ is not included because it was not subjected to comparable peer review. Its unusual findings are described and evaluated, however, because they too have received considerable attention.

Through this search process, we identified six publications that met the criteria for inclusion. We critiqued each of these studies by describing its methods and data sources and evaluating its strengths and limitations. Consideration of the methods and data permitted us to assess the studies' validity. The authors of each study explicitly interpreted their findings in terms of the percentage of personal health expenditures devoted to smokingrelated care, which allowed us to evaluate the consistency of the estimates in terms of the share of health expenditures devoted to smoking-produced disease. Finally, we compared findings across all of the studies, looking for consistent strengths and problems.

There are many unpublished analyses of the medical costs of smoking, as well as peer-reviewed publications that address the issue in a manner diverging from the interests of this paper-for example, evaluating the healthcare costs of smoking to individual smokers $^{9}$ or analysing the external costs of smoking ${ }^{7}$ ). Interested readers are referred to the articles we examine in this paper for descriptions of and references to these additional contributions.

FINDINGS, INDIVIDUAL STUDIES

The essential characteristics of each study are presented in table 1, including the smoking-related diseases included, study method, and principal data sources. Here we comment briefly on the methods of each study.

The first paper, published in 1978 by Luce and Schweitzer, ${ }^{6}$ used previously reported epidemiological and economic findings to generate its estimate of the cost of smoking. The proportions of the primary smoking-related illnesses caused by smoking were taken from the consensus of a panel of experts at a National Institutes of Health conference, as reported by Boden. ${ }^{15}$ These "smoking factors" were then applied to Cooper and Rice's 1976 cost-of-illness estimates, ${ }^{16}$ an early application of the pioneering work by Rice ${ }^{17}$ in evaluating the direct medical and indirect productivity costs of all major categories of disease. The resultant estimate of smoking-related healthcare costs of US $\$ 8.2$ billion in 1976 dollars constituted $7.8 \%$ of that year's direct medical expenditures in the United States. (See table 2.)

Seven years later, the OTA produced the next major estimate, ${ }^{13}$ widely cited for years thereafter. Using estimates derived from the American Cancer Society's cancer prevention study, a six-year prospective study of nearly a million Americans, ${ }^{18}$ OTA applied the relative risk of mortality from smoking-induced illnesses to the prevalence of smoking to estimate the number of deaths caused by smoking. A refinement introduced by OTA was the calculation and use of age-specific and sexspecific attributable risks. The attributable 
Table 1 Characteristics of American studies of medical costs of smoking

\begin{tabular}{|c|c|c|c|c|}
\hline Authors & $\begin{array}{l}\text { Date of } \\
\text { paper }\end{array}$ & Included disease categories & Method & Data \\
\hline $\begin{array}{l}\text { Luce and } \\
\text { Schweitzer }\end{array}$ & 1978 & $\begin{array}{l}\text { Cancer, circulatory system, } \\
\text { respiratory system, } \\
\text { accidents }\end{array}$ & $\begin{array}{l}\text { Estimated proportion of each disease caused by } \\
\text { smoking ("smoking factor") applied to personal } \\
\text { health expenditures for neoplasms, circulatory, } \\
\text { and respiratory diseases. }\end{array}$ & $\begin{array}{l}\text { Boden's smoking factors applied to Cooper and } \\
\text { Rice's estimates of personal health expenditures for } \\
\text { neoplasms, circulatory and respiratory diseases. }\end{array}$ \\
\hline $\begin{array}{l}\text { Office of } \\
\text { Technology } \\
\text { Assessment }^{13}\end{array}$ & 1985 & $\begin{array}{l}\text { Cancer, cardiovascular, } \\
\text { respiratory system }\end{array}$ & $\begin{array}{l}\text { Age, sex, disease specific smoking-related } \\
\text { mortality factors applied to age and sex specific } \\
\text { personal health expenditures for neoplasms, } \\
\text { circulatory, and respiratory diseases. }\end{array}$ & $\begin{array}{l}\text { Smoking factors derived from the ACS } 25 \text { state } \\
\text { study and NCHS mortality counts, with input from } \\
\text { the Framingham study, applied to Hodgson and } \\
\text { Kopstein's estimates of personal health } \\
\text { expenditures for neoplasms, circulatory and } \\
\text { respiratory diseases. }\end{array}$ \\
\hline $\begin{array}{l}\text { Rice, Hodgson, } \\
\text { Sinsheimer, et } \\
a l^{20}\end{array}$ & 1986 & $\begin{array}{l}\text { Cancer, circulatory system, } \\
\text { respiratory system }\end{array}$ & $\begin{array}{l}\text { Smokers' age, sex, and health service specific } \\
\text { attributable risks of medical care use for } \\
\text { neoplasms, circulatory and respiratory diseases } \\
\text { applied to personal health expenditures for } \\
\text { neoplasms, circulatory and respiratory diseases. }\end{array}$ & $\begin{array}{l}\text { Attributable risks of medical care use derived from } \\
\text { NHIS smoking supplement applied to Hodgson } \\
\text { and Kopstein's estimates of personal health } \\
\text { expenditures for neoplasms, circulatory and } \\
\text { respiratory diseases. }\end{array}$ \\
\hline $\begin{array}{l}\text { Bartlett, Miller, } \\
\text { Rice, et al }{ }^{22}\end{array}$ & 1994 & $\begin{array}{l}\text { Heart disease, emphysema, } \\
\text { arteriosclerosis, stroke, } \\
\text { cancer; also other health } \\
\text { status effects }\end{array}$ & $\begin{array}{l}\text { Multi-equation econometric model estimates } \\
\text { smoking attributable percentages, controlling } \\
\text { for smoking status, medical conditions, health } \\
\text { status, and various socioeconomic and } \\
\text { demographic factors. Percentages applied to } \\
\text { HCFA personal health expenditures. }\end{array}$ & $\begin{array}{l}\text { NMES household survey and NMES medical } \\
\text { provider survey; HCFA personal health } \\
\text { expenditures by health service type (hospitals, etc). }\end{array}$ \\
\hline $\begin{array}{l}\text { Miller, Zhang, } \\
\text { Rice, et al }{ }^{23}\end{array}$ & 1998 & $\begin{array}{l}\text { Heart disease, emphysema, } \\
\text { arteriosclerosis, stroke, } \\
\text { cancer; also other health } \\
\text { status effects }\end{array}$ & $\begin{array}{l}\text { Probit probability model estimates smoking } \\
\text { attributable fractions (SAF), controlling for } \\
\text { socioeconomic, demographic, behavioural } \\
\text { factors. SAFs applied to state medical } \\
\text { expenditures. National expenditures are sum of } \\
\text { state expenditures. }\end{array}$ & $\begin{array}{l}\text { NMES to estimate national SAFs; BRFSS to } \\
\text { estimate state SAFs, HCFA estimated state medical } \\
\text { expenditures. }\end{array}$ \\
\hline $\begin{array}{l}\text { Miller, Ernst, and } \\
\text { Collin }^{24}\end{array}$ & 1999 & All (not limited) & $\begin{array}{l}\text { Two-equation econometric model estimates } \\
\text { medical expenditure SAFs, controlling for } \\
\text { socioeconomic, demographic, and behavioural } \\
\text { factors. SAFs applied to state medical } \\
\text { expenditures. National expenditures are sum of } \\
\text { state expenditures. }\end{array}$ & $\begin{array}{l}\text { NMES to estimate national SAFs; TUS, BRFSS, } \\
\text { CPS, and NMES to construct state-level data set; } \\
\text { HCFA estimated state medical expenditures. }\end{array}$ \\
\hline
\end{tabular}

ACS = American Cancer Society; BRFSS = Behavioral Risk Factor Surveillance System; CPS = current population survey; HCFA = Health Care Financing Administration; NCHS = National Center for Health Statistics; NHIS = national health interview survey; NMES = national medical expenditure survey; TUS = tobacco use supplement of the CPS.

risks of mortality used by OTA for two of the major disease categories, cardiovascular and neoplasms, differed substantially from those used by Luce and Schweitzer. OTA attributed half as many circulatory deaths to smoking but $60 \%$ more deaths among neoplasms. Estimates of the morbidity toll were then made based on this same set of attributable risks. The cost estimate was produced by applying the attributable risks to age-specific and sexspecific cost-of-illness estimates presented by Hodgson and Kopstein. ${ }^{19}$ The proportion of expenditures attributed to smoking by OTA was similar to the proportion of deaths for neoplasms and circulatory diseases. For respiratory diseases, however, OTA set the attributable risk for expenditures at half that for mortality (24 v 48\%), believing that the mortality attributable risk was too high. Despite these differences from Luce and Schweitzer's study, the net effect on the overall cost-of-smoking estimate was modest when compared with that of the earlier research because differences by disease offset each other. OTA's estimate of $\$ 21.6$ billion in 1985

Table 2 Estimates of smoking-related expenditures as a percentage of total personal health expenditures, United States

\begin{tabular}{|c|c|c|c|}
\hline Authors & $\begin{array}{l}\text { Year of } \\
\text { estimate }\end{array}$ & $\begin{array}{l}\text { Estimated smoking-related } \\
\text { expenditures ( } \$ \text { billion) }\end{array}$ & $\begin{array}{l}\% \text { of Personal } \\
\text { health expenditures }\end{array}$ \\
\hline Luce and Schweitzer ${ }^{6}$ & 1976 & 8.2 & 7.8 \\
\hline Office of Technology Assessment ${ }^{13}$ & 1985 & 21.6 & 6.0 \\
\hline Rice, Hodgson, Sinsheimer, et al ${ }^{20}$ & 1984 & 23.3 & 6.8 \\
\hline Bartlett, Miller, Rice, et al ${ }^{22}$ & 1993 & 50 & 7.1 \\
\hline Miller, Zhang, Rice, et al ${ }^{23}$ & 1993 & 72.7 & 11.8 \\
\hline Miller, Ernst, and Collin ${ }^{24}$ & 1993 & 53.4 & $6.5^{\star}$ \\
\hline
\end{tabular}

${ }^{\star}$ This is the overall weighted average smoking-attributable fraction of expenditures. dollars represented about $6 \%$ of that year's total personal health expenditures. (See table 2.)

A year after the OTA study was released, Rice et $a l^{20}$ refined the attributable risk methodology by basing the estimates on the differential use of hospital and physician care for neoplasms and circulatory and respiratory diseases in the national health interview survey (NHIS) by groups distinguished by age, sex, and smoking status (current, former, never-smoker). These attributable risks were then applied to healthcare expenditures for neoplasms and circulatory and respiratory diseases in Hodgson and Kopstein ${ }^{19}$ to calculate the direct medical costs of smoking. The authors thus estimated the medical costs of smoking at $\$ 23.3$ billion in 1984 dollars, $6.8 \%$ of that year's total personal health expenditures.

In 1993, the OTA presented testimony at a Congressional hearing reporting a much lower percentage of personal health expenditures attributable to smoking. ${ }^{14}$ As noted above, we do not include this analysis among the studies formally selected for review because it was not subjected to peer review. We consider it here, however, because its findings have been cited frequently.

In this re-analysis, OTA reported the medical costs of smoking to have been $\$ 20.8$ billion in 1990 dollars, or $3.5 \%$ of total personal health expenditures. Compared with the finding in OTA's first study, ${ }^{13}$ this proportionately lower estimate resulted from OTA's modifying the estimation procedure used in the 1985 analysis. Whereas the previous study had used mortality attributable risks in calculating morbidity costs, the update 
used the SAMMEC program (smoking attributable mortality, morbidity, and economic costs) $)^{21}$ to calculate specific "risks" of ill people's using health services dependent on smoking status. SAMMEC incorporated estimates of health service utilisation by ever-smokers and never-smokers in the national health interview survey who were suffering from any of the three major categories of smoking-related chronic disease (cancer, cardiovascular disease, and respiratory disease). However, the program failed to consider smokers' greater likelihood of incurring these diseases (it included only people who had preexisting smoking-related diseases). ${ }^{21}$ OTA staff acknowledged the need for some refinements in the SAMMEC model and indicated that an updated estimate of the costs of smoking could be produced once the refinements had been completed, although we are unaware of the existence of such an update. Given this problem, we believe that this re-analysis suffered from a major flaw in its execution.

The following year, Bartlett et $a^{22}$ published a new estimate of the medical costs of smoking that derived from a model using novel and sophisticated estimation techniques and a database not previously used in cost-ofsmoking estimates, the 1987 national medical expenditure survey. Rather than using the conventional approaches to estimating and then "pricing" attributable risk, the researchers developed a multi-equation econometric model that adjusted smokers' differential use of health care by their risk profiles (controlling for risk factors other than smoking that might differentiate smokers from non-smokers), their overall (self-reported) health status, and their "taste" for utilisation of healthcare services. The last of these was intended to control for the possibility that smokers' and non-smokers' health care utilisation differs for some reason unrelated to either health or smoking status per se and not captured in the controlled risk factors; for example, smokers' personalities might lead them to use less health care than comparably healthy non-smokers. One would not want to attribute to smoking any differences in utilisation and expenditures resulting solely from such "tastes" for health care. By controlling for all these influences, this study focused on the link between smoking and excess health care utilisation, controlling for extraneous factors that might incorrectly inflate uncontrolled estimates of the costs of smoking. Bartlett et al concluded that smoking was responsible for $\$ 50$ billion in 1993 dollars, or $7.1 \%$ of personal health expenditures.

In 1998, with the assistance of a fourth colleague, three of the authors of the Bartlett et al study published a new analysis ${ }^{23}$ intended in part to update and correct the original analysis. In this new study, Leonard Miller et al estimated 1993 medical costs attributable to smoking at $\$ 72.7$ billion, $45 \%$ higher than in the previous study. With corrections in the denominator (the total of personal health expenditures covered by the study), the authors concluded that smokingattributable costs equaled $11.8 \%$ of personal medical expenditures for that year.
Although the conceptual approach of Miller et al was similar to that of Bartlett et al, several estimation procedures differed. In particular, rather than using five separate tobacco-related disease equations, as had Bartlett et al, Miller and colleagues used a single tobacco-related disease equation. Second, the authors corrected for errors deriving from a software procedure in the original study. The authors also noted three other differences between the two studies' methods. Especially important in explaining the large difference between the two studies' findings, the authors reported, was a mistake in the first study in which the authors failed to consider medical costs associated with smokers' generally poorer health status that are attributable to smoking. Rather, they controlled for health status and compared smokers' expenditures with those of hypothetically otherwise identical non-smokers (with the same profile of risk factors, etc, including the same self-reported health status). Miller et al have concluded that the study by Bartlett et al thereby substantially underestimated the true medical costs of smoking (oral communication with Drs Zhang, Rice, and Max, 15 September 1998).

In 1999, Vincent Miller (no relation to Leonard) and two colleagues published their findings from another econometric analysis of the smoking-attributable fractions (SAFs) of medical expenditures, again using the 1987 national medical expenditure survey (NMES) ${ }^{24}$ Using a more direct approach to estimating expenditure SAFs than that used by Leonard Miller et al, the new study concluded that $\$ 53.4$ billion was spent on smokingrelated diseases in the United States in 1993, based on an overall SAF of $6.5 \%$.

Reasonably consistent with the findings of Bartlett et al, this most recent study yielded results well below those of Leonard Miller et al. Although the differences have yet to be reconciled, the study by Vincent Miller and his colleagues produced an anomalous finding that may eventually help to explain the difference. Vincent Miller et al reported: "In the utilisation model, the hospital SAF is almost twice that of the ambulatory SAF, while in the expenditure model, the relative magnitudes are reversed." The authors interpreted the difference as follows: "These results imply that smokers spend, on average, more than non-smokers on ambulatory visits ... but spend less per day on hospital stays (less intensive hospital stays)" (page 385). The authors also observed that the utilisation SAFs derived from the NMES data are consistent with those found using national health interview survey data.

We find unconvincing the authors' explanation of why the hospital expenditure SAF should be less than the utilisation SAF. It rests on their assertion that smoking-related hospital stays are less intensive than other hospital stays, indeed far less intensive. In theory, this could result if smoking-related diseases involve much less intensive hospital resource utilisation than do other diseases. Alternatively (or in addition), it could result if smokers (and their physicians) use many fewer resources 
during their hospitalisations than do nonsmokers for either smoking-related or other diseases, either because the smokers are less ill than the non-smokers or because they simply choose to use less care. To test the first hypothesis, using three different data sets we compared hospital cost per day for lung cancer and chronic obstructive pulmonary disease, two diseases caused primarily by smoking, with hospital cost per day for all causes. In each of the comparisons, the daily smoking-related hospitalisation costs exceeded the average for all hospital days (unpublished results available from authors on request). The second hypothesis is disproved by the NMES survey in which there is virtually no difference in daily hospital costs between smokers and non-smokers. Given these results, we see no reason to expect that utilisation SAFs should exceed expenditure SAFs, at least by such a wide margin. More complete appreciation of the findings of Vincent Miller et al must therefore await an explanation of this apparent inconsistency in SAFs.

INTERPRETING THE FINDINGS

In terms of their methodological approaches, the six reviewed studies group into two categories. The first three focus on the amount of disease caused by smoking for the principal smoking-related diseases, based on epidemiological criteria, and the amount of health care utilisation and expenditure associated with that disease burden. In contrast, the three more recent studies were all intended to estimate smokers' total excess expenditures over those of non-smokers, including the major smokingrelated diseases and other smokingattributable costs, with variations in the methods for comparing smokers' and non-smokers' expenditures (discussed below).

Logically, one can read the results in table 2 as suggesting a strong consensus that smoking accounts for something between 6 and $8 \%$ of American medical costs, with the study by Leonard Miller et al ${ }^{23}$ an outlier. As we discuss below, however, when one accounts for mistakes in Bartlett et $a l^{22}$ identified by the authors in their more recent work, ${ }^{23}$ the possible problem with the SAFs in the study by Vincent Miller $e t a l,{ }^{24}$ and additional evidence from a related study, ${ }^{10}$ we find a distinct possibility that smoking-related expenditures attributable to other than the major smoking-related diseases may account for a significant increment to the percentage of total healthcare expenditures. That is, we read the evidence as implying that $6-8 \%$ may be an underestimate of the true total medical costs of smoking in the United States We emphasise, however, that before the $6-8 \%$ range should be considered an underestimate, additional empirical research will be needed.

The consistency of the findings in the first three studies ${ }^{61320}$ reflects similarities in perspective and basic methods, with each focusing on the three major categories of smoking-attributable disease. The relative consistency across epidemiological studies of findings about the major illness consequences of smoking ${ }^{18}$ lends consistency to the estimates in the body of research on costs. Nevertheless, this consistency across epidemiological studies is far from perfect. The similarity of bottom-line findings in the Luce and Schweitzer and OTA studies actually masks rather different attributable risk fractions for the major smoking-related diseases, with Luce and Schweitzer crediting smoking with $20 \%$ of neoplasms, compared with $31 \%$ in the OTA study, $25 \%$ of circulatory diseases, compared with OTA's $15 \%$, and $40 \%$ of respiratory illness, versus $24 \%$ for OTA. The lack of much difference in bottom-line cost estimates reflects the fact that these disease-specific differences largely negate each other.

Costing out the disease implications of smoking entails "pricing" medical treatment of those diseases, which draws heavily on the well-defined cost-of-illness (COI) literature. This literature owes a special debt of gratitude to the seminal work of Rice and her colleagues. ${ }^{1617}$ Given Rice's involvement in COI estimation, it is hardly surprising to find her and close colleagues playing central roles in applying COI findings to a major behavioural cause of morbidity and mortality. These roles have extended beyond the most obvious one of authorship, as these individuals were involved in the review of the 1985 OTA analysis and in the development of methods used in OTA's 1993 update (the SAMMEC program).

The overlap in authorship and, in several studies, methods is not necessarily a source of concern, although it does recommend careful consideration of any systematic biases that might have become entrenched within the literature. Notable in the present literature, however, is the evolution and refinement of methods by authors immersed in the issue, culminating in the sophisticated econometric approaches embodied in the work of Bartlett et $a l^{22}$ Leonard Miller et $a l^{23}$ and Vincent Miller et al. $^{24}$

The findings from two analyses not included in our formal review, the revised OTA study prepared for Congressional testimony ${ }^{14}$ and a 1992 paper by Hodgson, ${ }^{10}$ give pause, however, for opposite reasons. The OTA update raises questions, given its extraordinarily low estimate of smoking-attributable costs, compared with the estimates in all of the other studies. As is demonstrated below, Hodgson's study, a life-cycle analysis of smoking-related medical expenditures, implied an extraordinarily high estimate (14\%). A natural question is whether this results from the study's different methodological approach and purpose. We turn to that question after considering the validity, and hence implications, of the revised OTA analysis.

The methodological modification made by OTA, estimation of condition-specific attributable risk of health services utilisation, was clearly correct in concept. We question whether it was executed accurately, however. The smoking-attributable fractions used by OTA (found in table 10 of OTA's testimony) indicate, for example, that although smoking is responsible for about $50 \%$ of cancer deaths in 
men under age $65,30 \%$ of circulatory disease deaths, and $23 \%$ of respiratory disease mortality, it accounts for only $9 \%$ of physician services. Similarly, for men 65 and older, smoking is deemed responsible for $41 \%$ of cancer mortality, $9 \%$ of circulatory disease deaths, and $28 \%$ of respiratory disease deaths; yet the estimated smoking-attributable fraction of medication costs is $5 \%$. As one final example, for women under age 65 , smoking is estimated to account for approximately a quarter of each of the three disease categories' deaths; yet the SAMMEC-indicated estimate for hospitalisation utilisation is $5 \%$, with physician services utilisation estimated at $8 \%$.

In virtually all cases, the smokingattributable direct cost fractions fall short of the smoking-attributable mortality fractions. Qualitatively, this is plausible. Smoking-related conditions may be more rapidly fatal, with fewer useful medical interventions available, than is the case for other diseases within these chronic disease categories. For example, compared with many other cancers, lung cancer has a relatively short duration until a high-probability death, and there is little that medical intervention can do to alter the eventual outcome. Conceivably, a higher proportion of smokers with heart disease die as a result of their illnesses than do non-smokers with heart disease, leaving more of the latter to consume healthcare services. On the other hand, however, some smoking-related conditions likely entail a great deal of medical care, such as emphysema.

Socioeconomic differences between smokers and non-smokers could also account for differences in health care utilisation, quite independent of health status. More affluent individuals may use more health services. In the United States, more affluent people are less likely to be smokers.

Another plausible explanation for the phenomenon lies in the fact that the respondents to the survey are not in nursing homes at the time they are surveyed. (The national health interview survey queries only members of the civilian non-institutionalised population.) If smokers are disproportionately represented in the institutionalised population, as seems plausible, their relative utilisation of healthcare services will be under-represented in the survey data. With the institutionalised a small fraction of the total population, this is likely to be a small effect. However, it could be significant with regard to hospital and nursing home stays.

We conclude, therefore, that it is quite possible, perhaps even likely, that the smokingattributable fractions of health care utilisation, as measured by SAMMEC, should be lower than the smoking-attributable fractions of mortality. However, the magnitudes of the differences, illustrated above, strike us as not plausible. This observation is supported by Rice et $a l^{20}$ who report generally higher attributable fractions for health care utilisation than OTA. For example, for women under age 65, Rice et al find $30 \%$ of hospital days for neoplasms and circulatory and respiratory dis- eases attributed to smoking compared with only $5 \%$ by OTA. If this interpretation is correct, the implication is that, by calculating attributable risks among persons who were already suffering from any of the three major categories of smoking-related disease, the 1993 OTA analysis likely underestimated the medical costs of smoking for 1990. In contrast, based on their use of smoking-attributable mortality fractions to estimate health care utilisation, the earlier study by OTA may well have overestimated it.

From another perspective, however, the studies that relied on estimation of attributable risks based on "early" epidemiological studies might have been underestimating the cost of smoking. For example, the first OTA study ${ }^{13}$ noted that the attributable risk of smoking might actually be considerably higher than the estimates produced from the American Cancer Society's cancer prevention study data, the source of OTA's mortality estimates, as smoking behaviours had changed considerably over the course of the century. ${ }^{18}$ In particular, as the age of initiation of smoking declined, and as people began smoking more intensively-for example, more cigarettes per day-the risks might be expected to have increased. Covering the period 1959-65, the ACS study was picking up deaths among people born around the turn of the century. Many of them would have started smoking as young adults, often in their mid-20s to early-30s, rather than as teenagers. Particularly worthy of note were changes in smoking behaviour among women, for whom smoking was a very rare behaviour during the early part of the century, and hence smoking-related death a much less common phenomenon than at present. As such, in this dimension at least, the cost-of-smoking analyses that relied on the ACS data likely were underestimating the importance of smoking in mortality, and hence quite possibly in health care utilisation.

Data from the ACS's more recent cancer prevention study (CPS) II, covering 1982-86, confirm this suspicion. ${ }^{18}$ The overall relative risk of death for currently smoking males rose from 1.80 to 2.34 from CPS I to CPS II; for females, the comparable figures were 1.23 to 1.90. For smoking's "marker" disease, lung cancer, the risks rose from 11.35 to 22.36 for men and 2.69 to 11.94 for women. Earlier, more intensive smoking greatly increased the risks of smoking for both sexes. Particularly worthy of note is that the generation of women dying from smoking during the mid-1980s, the time of CPS II, had smoking histories, and associated mortality outcomes, very similar to those of the men dying from smoking during the early 1960s, the era of CPS I. Specifically, the relative risks of death for all-causes and lung cancer for women in CPS II are virtually identical to those of men in CPS I.

Reliance on the earlier smoking mortality data likely contributed to an underestimation of the costs of smoking. Rice et al provide some support for this assessment, attributing $23 \%$ of expenditures for the three major diseases to smoking compared with $20 \%$ in the OTA 
analysis, accounting for $6.8 \%$ of public health expenditures versus $6 \%$ (table 2 ). Although it is beyond the scope of this review to determine how much these kinds of considerations might have influenced the estimates of the medical costs of smoking, we suspect that the net effect is modest. We also conclude that the findings presented in OTA's 1993 testimony, deriving from implausibly low healthcare utilisation fractions, are not credible.

Along with the more recent work of Leonard Miller and colleagues, ${ }^{23}$ Hodgson's study ${ }^{10}$ poses a more significant challenge to the consensus finding that smoking-attributable costs fall in the range of $6-8 \%$ of personal health expenditures. The challenge is not "visible", however, in that Hodgson did not frame his results in the context of smoking's share of personal health expenditures. Hodgson focused not on a prevalence-based estimate of expenditures on medical care associated with smoking, but rather on an incidence-based examination of the future medical costs of smoking and of not smoking. This work was designed to address the controversial question of whether the longer lives of never-smokers generate healthcare costs that compensate for the higher annual costs of ever-smokers during their fewer number of years of life. The substance and implications of this controversy are discussed later in this paper.

Hodgson's paper also differs from the three reviewed papers that preceded its publication $^{6}{ }^{1320}$ for another important methodological reason. Rather than examining the smoking-attributable fractions of the costs of treating the major smoking-related diseases, Hodgson examined differences in all healthcare expenditures for smokers (current and former) and never smokers, the first such study to do so. This method has the virtue of capturing smoking-related expenditures that are missed by other studies that examine only the major smoking-related illnesses. As is discussed below, these additional smoking-related expenditures may be considerable. However, comparing the expenditures of ever-smokers and never-smokers introduces the risk of attributing excess medical expenditures to smoking that ought to be attributed to other risk factors correlated with smoking status. For example, it is well known that today's smokers are much more prone to risk-taking behaviour in general than are non-smokers. ${ }^{25}$ They drink more alcohol, exercise less, and even drive closer to cars in front of them than do non-smokers. This is why Bartlett et al, ${ }^{22}$ Leonard Miller et $a l,{ }^{23}$ and Vincent Miller et $a l^{24}$ controlled for several other risk factors in their studies of 1993 costs. Hodgson acknowledged this concern, but observed that Manning et al had concluded that controlling for other risk factors reduced the difference between smokers' and nonsmokers' medical costs by only $13 \%$.

Despite the critical distinction in perspective, purpose, and method, Hodgson's study generated an estimate of the medical cost of smoking that can be compared reasonably directly with analyses using smokingattributable disease fractions and employing a prevalence-based annual perspective. Specifically, he calculated the costs of smoking over the next five years by comparing the total healthcare costs of the existing mix of ever-smokers and never-smokers with the total costs that would have been realised had the entire population had the cost (and survival) profiles of the never-smokers only. Because five years does not represent a long enough time to begin to observe significantly larger numbers of (never-smoking) elderly, this net cost of smoking figure is quite comparable to the gross cost of smoking estimates produced in the other studies. Averaging over the five-year period, Hodgson's analysis implies annual medical expenditures of $\$ 40.6$ billion in undiscounted 1990 dollars. Adjusting this figure for the impact of other risk factors correlated with smoking status reported by Manning et al, smoking attributable expenditures equaled about $14 \%$ of the cost of hospital, physician, and nursing home services that Hodgson's analysis considered.

Why might all-cause smoking-attributable expenditure greatly exceed that associated only with the major smoking-related diseases? The answer reflects on the highly systemic effects of smoking and the secondary impacts existing smoking-related diseases have on health services utilisation and expenditures. First of all, smoking plays a role in the causation of multiple diseases not included among the "big three." A partial list, spanning a variety of organ systems, includes: skin conditions (psoriasis), orthopaedic problems (disc degeneration), musculoskeletal and connective tissue diseases (osteoporosis and osteoarthritis), diseases of the genitourinary system (impotence), vision problems (cataracts, macular degeneration, optic neuropathy), gastrointestinal conditions (ulcers, Crohn's disease), hearing loss, and oral problems (periodontal disease) ${ }^{26}$ In terms of hospital utilisation, this sample of less publicised conditions accounts for a fifth as many inpatient days as neoplasms and circulatory and respiratory diseases. ${ }^{27}$ Although clearly this role is not comparable to that of the "big three" diseases, since they account for the vast majority of smokingattributable mortality, equally clearly it adds to the expenditure burden properly attributable to smoking. None of the studies reviewed in this paper that predate the Hodgson analysis captured these smoking-produced costs.

Second, smoking plays a less well-known role in mediating the outcomes of other diseases and disease treatments that few people associate with smoking per se. Smokers with existing smoking-related diseases will be at higher risk of utilisation of services for non-smoking-related diseases. For example, people with chronic disease caused by smoking are more likely to be hospitalised and use other health services for non-smoking-related diseases because of the greater difficulty of managing these diseases. Once hospitalised, smoking-related comorbidities will make hospital stays longer and cause more medications and procedures to be used. Similarly, more time will be spent with the 
patient in the doctor's office, and more tests and procedures may be required. To illustrate, although analysis documenting this for smoking-related conditions has not been undertaken, the impact of secondary diabetes on health expenditures has been evaluated and found to be significant. ${ }^{28-30}$ Hospital inpatients have 2.5 times as many secondary as primary diagnoses for neoplasms, cardiovascular disease, and respiratory disease. ${ }^{27}$ If $23 \%$ of secondary diagnoses are due to smoking (as reported by Rice $e t \mathrm{al}^{20}$ ) and add one day to the average length of stay, or its equivalent in other costs of inpatient care, expenditures for hospital care attributed to smoking increase by $40 \%$. Although the exact quantitative association is unknown, we expect smoking-related diseases also increase the amount of health care required for unrelated conditions.

As a final illustration, compared with non-smokers, smokers have worse outcomes and longer recovery periods (often entailing longer hospitalisations) for surgeries unrelated to smoking per se. ${ }^{26}$ Smoking-related conditions require that additional resources be expended for unrelated diseases in a variety of ways. Clearly, all such excess medical expenditures are smoking-related and ought to be counted in assessing smoking-attributable healthcare costs.

For these reasons, Hodgson's analysis is consistent with the view that the studies that find smoking's contribution to medical care costs ranging from $6-8 \%$ may have underestimated the contribution, possibly considerably. One should not conclude from this single analysis that smoking accounts for $14 \%$ of healthcare expenditures. The principal lesson of this work, rather, is that the $6-8 \%$ figure deriving from five of the six studies reviewed in this paper may represent a lower bound, rather than a central tendency. It may well be a plausible estimate of the medical costs attributable to the three leading smoking-related diseases. Hodgson's estimate of $14 \%$ might reasonably be considered an upper bound on smoking's total contribution to healthcare costs. The proximity of the estimate of Leonard Miller et al-11.8\%-lends support to the notion that the aggregate medical expenditure burden of smoking may exceed the $6-8 \%$ range by quite a bit, although the recent finding of Vincent Miller et al-6.5\%recommends caution.

Further research will be needed to hone in on a more precise estimate. The contribution of the more recent studies is to suggest improvements in estimation techniques that should permit a more accurate assessment of the real medical costs of smoking. Note, however, that even an analysis that incorporates all of these insights will not necessarily capture all such costs. Notably, no study performed to date has included medical expenditures attributable to diseases caused or exacerbated by environmental tobacco smoke (ETS) exposure. If recent estimates of the disease and mortality burden of ETS are accurate, ${ }^{31}$ ETS-related healthcare costs could increase the share of health expenditures attributable to smoking by as much as a percentage point.
Relevance of American analyses to the costs of smoking in other countries

Analysts have undertaken cost-of-smoking studies in several countries, although few countries boast more than one such published study, and these are found almost exclusively in Western developed nations, such as Canada. ${ }^{32-34}$ Analyses of the medical costs of smoking in developing countries are particularly scarce, ${ }^{35}$ with recent work in China constituting an important exception to the rule. ${ }^{36}$ Given this dearth of empirical evidence elsewhere, it seems particularly important to determine what lessons can be drawn from the American experience with this form of analysis.

The basic methodological approach used in the first three American studies ${ }^{6}{ }^{13}{ }^{20}$ is highly similar to that which has been used in other countries. One might suspect, with some justification, that this results from analysts mimicking the approach of colleagues in other countries. In part, however, it simply follows directly from the inherent logic of the dominant methodology: to perform such analysis, the analyst typically estimates the amount of illness attributable to tobacco, usually focusing on the major smoking-disease relationships, and then values the medical treatment that would be afforded victims of such diseases. Alternatively, the analyst examines disease-specific healthcare utilisation directly, and then values it. That this method misses some potentially important costs of smoking has not, to our knowledge, been considered elsewhere. We anticipate that the recent contributions to the American literature, ${ }^{22-24}$ refocusing the analysis on healthcare expenditure differences between smokers and non-smokers, eventually will become the norm in cost-of-smoking analyses in countries throughout the world.

The same methodology will not produce the same quantitative outcomes in different countries, reflecting three country-specific factors that strongly influence the estimates.

- Differences in the amount of tobacco-related disease. These will result from at least five characteristics that vary across nations:

- a country's history of tobacco use, including the nature of use, such as smoking versus chewing, age of initiation, intensity of use-for example, cigarettes per daylikely to be relatively low in a poor country, and length of period of intense use, such as how long consumers have been heavy smokers, typically a relatively brief period in a poorer nation;

- the age structure of the country's population, with older populations more subject to tobacco-related disease (controlling for tobacco use);

- competing causes of disease within the population, with countries subject to more deaths from other causes prior to age 60 less likely to experience a large burden of tobacco-produced (and other chronic) disease mortality;

- the presence and effects of infectious and environmental co-factors in disease; 
tobacco use amplifies the outcomes of many common risk factors and diseases and vice versa; for example, death rates due to tuberculosis are two to three times higher in smokers than in non-smokers; asbestos exposure and smoking interact to cause lung cancer and other pulmonary diseases; and chronic obstructive lung disease in smokers and non-smokers is exacerbated in populations exposed to high levels of indoor air pollution, as in China where people burn charcoal in their homes for cooking and heating and where smoking by men is commonplace ${ }^{18}{ }^{38}$;

- possible variations in the extent of the disease-causing properties of tobacco use across the different societies reflecting, for example, the specific blend of tobaccos consumed or the construction of cigarettes (the depth of inhalation they permit or encourage, etc).

- Differences in how often, and how aggressively, various disease conditions are treated. On average, smoking-related diseases may be less likely to be treated, especially aggressively, in a developing country than in a developed one. This could reflect a mix of philosophical and cultural differences in approaches to health care, and access to care issues related to the differential availability of healthcare facilities and financial access to services.

- Differences in the costs of such treatments and in their effectiveness. Again on average, treatments in poor countries may be less effective and less expensive than in affluent nations. (This will affect the share of health expenditures attributable to smoking differentially only if the relationship between costs and effectiveness for tobacco-related diseases and other illnesses varies from one country to another, as seems likely.)

These differences have particularly important implications for developing nations. In general, they imply that medical expenditures attributable to tobacco will increase, in many instances dramatically, as their regular tobacco use histories expand and as chronic disease health care becomes more effective, more accessible, and more expensive. Note that the conclusion that costs will grow will hold even in poorer countries that already have reasonably long histories of high prevalence of tobacco use, because the intensity of use in such countries is typically quite low while most of the population is mired in poverty. Historically, as they have moved from poverty toward affluence, nations have always experienced expanded daily tobacco consumption, with the consequent adverse implications for health.

Regardless of the precise comparability of the findings from one country to another (and among studies within individual countries), it is important to emphasise that the essential "bottom line" of all medical cost-of-smoking studies to date has been identical: in addition (and due) to causing alarming amounts of illness and death, tobacco use is responsible for a significant fraction of each studied nation's healthcare expenditures.
Net $v$ gross costs of smoking-related medical care

Precisely because smoking claims the lives of so many of its consumers, it has the seemingly perverse economic "benefit" of avoiding some healthcare costs by reducing the number of years during which people consume medical care. The implication is that the net medical cost of tobacco use-the increased costs of health care during smokers' lives, adjusted by the reduction in their non-smoking-related old-age healthcare costs due to their premature deaths - is almost certainly less than its gross cost; as noted above, however, the latter is what most analysts estimate.

The issue of the net $v$ gross cost of tobaccorelated medical care was first raised in 1983 in a study by two Swiss economists, Leu and Schaub. ${ }^{8}$ These authors simulated the medical cost history of Swiss men with and without cigarette smoking, concluding that the extra years of costs experienced by the longer-lived no-smoking cohort approximately balanced out the higher costs during each year of the smokers' (shortened) lives. A decade later, Hodgson $^{10}$ concluded that ever-smokers (current and former smokers) cost more in terms of lifetime medical expenditures than never-smokers; in this study, the higher annual costs of smokers outweighed the extra years lived by never-smokers. Hodgson also raised the prospect that smokers might even consume more healthcare resources during their years as senior citizens (65 and older), as they experience much more illness than neversmokers during these old-age years, even though the never-smokers live longer.

The most recent relevant study, an examination of the net medical costs of smoking in Finland, ${ }^{39}$ has accentuated growing interest in the gross $v$ net cost debate. ${ }^{40}$ Once merely a debating tool, medical cost estimates are becoming increasingly important in policy and legal matters. As noted at the beginning of this paper, most of the American states sued the tobacco industry to recover publicly funded expenditures devoted to the care of the poor non-elderly made ill by cigarette smoking. The states based their requests for damages on estimates of the gross medical costs of smoking. Several American cities filed suits of their own, as have private sector organisations. The federal government announced its intention to sue to recover its smoking-related Medicare costs. Similar suits are being contemplated, and in some instances have already been filed, in numerous countries around the world.

Economists working for the tobacco industry have argued that, if one accepts that smoking causes disease and premature death (a proposition they often do not acknowledge directly), one must incorporate the offsetting "benefit" of earlier deaths due to smoking to determine the true cost to the states. ${ }^{41}$ In the specific case of Medicaid, the principal programme in the United States supporting publicly funded care for the non-elderly poor, it seems unlikely that the earlier deaths would have a large impact on Medicaid spending on health care, simply because the programme's 
beneficiaries are chiefly young and middleaged people; the elderly are covered by Medicare, a federal government programme. However, Medicaid is also responsible for the nursing home costs of the indigent, including the elderly. Whether smoking imposes more or fewer financial obligations on the states in this domain is unknown. Presumably, by killing their consumers early, cigarettes reduce the number of people eligible for nursing home care. On the other hand, smokers who survive beyond 65 are sicker, on average, and hence more in need of nursing home care.

Tobacco control proponents in the United States, including many of the state attorneys general responsible for filing the Medicaid lawsuits, have dismissed the argument that one should consider the later medical costs of nonsmokers as an "excess" "cost" of not smoking. Some observers rightly point out that if one thought this way systematically, there would be no point in ever trying to solve any health problem that afflicts primarily the elderly; the economic "ideal" under this scenario would be to keep people healthy until they retire and then eliminate them. The concept places no value at all on life per se, in striking contrast to the value implicit in the behaviour of virtually all societies, which willingly expend resources to prolong healthy life well into the retirement years. (Note that if one's objective were to minimise a nation's healthcare costs, the solution would have nothing to do with smoking. It would be simple, if far more radical: prohibit the provision of all health care!)

The observation that societies value life well beyond the medical expenditures used to sustain it is undoubtedly correct. At the same time, the cost-of-tobacco argument rests on the premise that, quite independent of the health consequences of tobacco use or of the inherent value of life, tobacco is imposing a financial burden on the society. If the objective is to understand the true burdens associated with tobacco, it is vital that we distinguish the human and financial costs, and recognise that the latter must be fairly assessed for the purpose at hand. If the issue is how much of a financial burden tobacco imposes on a society, then one ought to examine the net costs, and not only the gross costs. At the same time, however, one ought to include as a benefit of non-smoking all contributions to funding the health care system made by non-smokers in their extra years of life. Furthermore, to put the issue of net versus gross costs into perspective, one should divide costs by the number of health system beneficiaries and, ideally, age-adjust. Regardless of their conclusions about the total net costs of smoking, all studies would find that the age-adjusted medical costs per capita are significantly lower without smoking than with it. Again, this is something that is rarely even mentioned in the literature published to date.

Each measure of the healthcare financial burden of tobacco - the gross and net medical care cost-has meaning and appropriate uses in the right context. The gross cost, the standard measure, is an accurate gauge of how much of its healthcare resources a country devotes to treating diseases produced by tobacco. That a country might prefer to devote these resources to alternative purposes, including additional health services for a longer-lived population of senior citizens, is perfectly sensible and legitimate. As such, estimation and dissemination of the gross cost are themselves informative and useful activities.

Adjusted to reflect contributions to the health care system in non-smokers' additional years of life (never done to date), the net cost would be the correct concept for assessing how much of a fiscal burden smoking places on a nation's health care system on balance, that is, considering its direct creation of disease and its consequent reduction in the population of the elderly. If the question of interest is exclusively how much greater a nation's healthcare expenditures are with smoking compared with the absence of smoking, the net measure is the logically correct one. One may question, however, why one would be interested in such a number devoid of the denominator of the number of people served or of the better health their expenditures buy.

\section{Conclusion}

The peer-reviewed literature on the medical costs of smoking in the United States indicates that at least $6-8 \%$ of annual personal health expenditures in the United States, and quite possibly considerably more, is devoted to treating diseases caused by smoking. The $6-8 \%$ figure represents a solid estimate of expenditures directly related to smoking's three most important disease causes of death, lung cancer, heart disease, and chronic obstructive pulmonary disease. Although technical analytical problems remain to be ironed out, the three most recent analyses reviewed in this paper ${ }^{22-24}$ suggest the means by which a more complete accounting of smoking's costs can be assessed. New research should incorporate the extra smoking-related costs of conditions affected by, but not generally recognised as caused by smoking, as well as medical expenditures on disease resulting from exposure to environmental tobacco smoke.

As smoking causes close to a fifth of all deaths in the United States, at first glance one might expect that smoking would account for a percentage of healthcare costs close to its share of deaths. That it almost certainly does not reflects the obvious fact that medical care is devoted to much in addition to death care and care for conditions potentially leading to death, including birth, paediatric care, primary and preventive care for adults, treatment of acute, non-fatal conditions ranging from broken bones to bacterial infections, and treatment of chronic but non-fatal conditions such as arthritis.

In other countries, the share of expenditures attributable to treating tobacco-related disease will differ. In all cases, however, it too is probably quite substantial. In developing countries, that share seems likely to grow over the next several decades, as these countries acquire longer histories of tobacco use and as the 
intensity of use rises with increasing affluence. Increasing availability of chronic disease treatment will increase expenditures on tobaccoproduced illness as well.

The debate over use of the gross or net healthcare cost of tobacco will persist and indeed intensify if its applicability extends beyond its predominant use to date, namely as a rhetorical device used by tobacco-control advocates. In particular, if the unique American state lawsuits against the tobacco industry gain currency worldwide, one can expect to see a battle royale over which concept, gross or net, should characterise the financial healthcare burden of tobacco to a state or nation.

In closing this review of the findings and meaning of the analysis of the medical costs of smoking, we wish to emphasise that whatever measure is used, the financial healthcare costs of smoking constitute only one indication of the burden of smoking on a society, in some ways a rather minor one. The most important outcome of tobacco use remains the one that underlies the estimates of monetary cost: the devastation it wreaks on human health. No economic measure has yet been devised to appropriately value that enormous burden. Years ago, one analyst attempted to compare the pain and suffering associated with a disease (cancer) with its conventionally measured economic costs. ${ }^{42}$ His study concluded that, could they be appropriately valued, the costs that are never assessed in monetary terms - the physical and emotional toll on the victims and their loved ones-could easily exceed those that economists measure by an order of magnitude. It is important not to lose sight of this as we struggle to refine estimates of that which can be measured.

The authors gratefully acknowledge the assistance of Wendy Max, Leonard Miller, Dorothy Rice, Xiulan Zhang, and Vincent Miller in reviewing previous drafts and discussing methodological issues, and the helpful suggestions of three anonymous referees. Preparation of this report was supported by a contract with Dr Warner from the Office on Smoking and Health, Center for Chronic Disease Prevention and Health Promotion, Centers for Disease Control and Prevention, and by Promotion, Centers for Disease Control and Prevention, and by
grant 026421 from the Robert Wood Johnson Foundation. The grant 026421 from the Robert Wood Johnson Foundation. The
report does not necessarily represent the opinions or report does not necessarily represent the opinions or
conclusions of the Office. Responsibility for all of the material in this report rests exclusively with the authors.

1 Hodgson TA, Meiners MR. Cost-of-illness methodology: a guide to current practices and procedures. Milbank Mem guide to current practice
Fund $Q$ 1982;60:429-62.

2 Jacobson PD, Warner KE. Litigation and public health policymaking: the case of tobacco control. F Health Polit Pol Law 1999;24:769-804.

3 Miller LS, Zhang X, Novotny T, et al. State estimates of Medicaid expenditures attributable to cigarette smoking, fiscal year 1993. Public Health Rep 1998;113:140-51.

4 Bloch M, Daynard R, Roemer R. A year of living dangerously: the tobacco control community meets the global settlement. Public Health Rep 1998;113:488-97.

5 Multistate settlement with the tobacco industry. www.tobacco.neu.edu/Extra/multistate_settlement.htm (accessed 27 August 1999)

6 Luce BR, Schweitzer SO. Smoking and alcohol abuse: a comparison of their economic consequences. $N \mathrm{Engl} F \mathrm{Med}$ 1978;298:569-71.

7 Manning WG, Keeler EB, Newhouse JP, et al. The taxes of sin. Do smokers and drinkers pay their way? FAMA 1989; 261:1604-9.

8 Leu RE, Schaub T. Does smoking increase medical expenditures? Soc Sci Med 1983;17:1907-14.

9 Oster G, Colditz GA, Kelly NL. The economic costs of smoking and benefits of quitting for individual smokers. Prev Med 1984;13:377-89.
10 Hodgson TA. Cigarette smoking and lifetime medical expenditures. Milbank $Q$ 1992;70:81-125.

11 Kristein MM. Economic issues in prevention. Prev Med 1977;6:252-64

12 Hedrick JL. The economic costs of cigarette smoking. HSMHA Health Rep 1971;86:179-82.

13 Office of Technology Assessment, US Congress. Smokingrelated deaths and financial costs. OTA staff memorandum. Washington, DC: Health Program, OTA, 1985.

14 Office of Technology Assessment, US Congress. Smokingrelated deaths and financial costs: Office of Technology assessment estimate for 1990. Statement of Herdman R, Hewitt M, Laschober M before the Special Committee on Aging, US Senate, 1993.

15 Boden LI. The economic impact of environmental disease on health care delivery. F Occup Med 1976;18:467-72.

16 Cooper BS, Rice DP. The economic cost of illness revisited. Soc Sec Bull 1976;39:21-34

17 Rice DP. Estimating the cost of illness. Health Economics Series No 6. Public Health Service Publication No 6. Washington, DC: US.Government Printing Office, 1966.

18 US Department of Health and Human Services. Reducing the health consequences of smoking: 25 years of progress. A report of the Surgeon General, 1989. Rockville, Maryland: on Smoking and Health, 1989. (DHHS Publication No (CDC) 89-8411.)

19 Hodgson TA, Kopstein AN. Health care expenditures for major diseases in 1980. Health Care Financing Review 1984;5:1-12.

20 Rice DP, Hodgston TA, Sinsheimer P, et al. The economic costs of the health effects of smoking, 1984. Milbank $Q$ 1986;64:489-547.

21 Shultz JM, Novotny TE, Rice DP. SAMMEC II: Computer software and documentation. Atlanta, Georgia: Centers for Disease Control, Office on Smoking and Health, 1990.

22 Bartlett JC, Miller LS, Rice DP, et al (US Centers for Disease Control and Prevention). Medical expenditures attributable to cigarette smoking-United States, 1993. MMWR 1994;43:469-72.

23 Miller LS, Zhang X, Rice DP, et al. State estimates of total medical expenditures attributable to cigarette smoking, 1993. Public Health Rep 1998;113:447-58.

24 Miller VP, Ernst C, Collin F. Smoking-attributable medical care costs in the USA. Soc Sci Med 1999;48:375-91.

25 US Department of Health and Human Services. The health benefits of smoking cessation. A report of the Surgeon General, 1990. Rockville, Maryland: Public Health Service, Centers for Disease Control, Office on Smoking and Health, 1990. (DHHS Publication No (CDC) 90-8416.)

26 Napier K. Cigarettes: what the warning label doesn't tell you. The first comprehensive guide to the health consequences of smoking. New York, New York: American Council on Science and Health, 1996.

27 Graves EJ, Gillum BS. Detailed diagnoses and procedures, National Hospital Discharge Survey, 1995. Vital Health Stat 1997;13:32-59.

28 American Diabetes Association. Direct and indirect costs of diabetes in the United States in 1992. Alexandria, Virginia: ADA, 1993.

29 Ray NF, Thamer M, Taylor T, et al. Hospitalization and expenditures for the treatment of general medical conditions among the US diabetic population in 1991. F Clin Endocrinol Metab 1996;81:3671-9.

30 Ray NF, Thamer M, Gardner E, et al. Economic consequences of diabetes mellitus in the US in 1997. Diabetes Care 1998;21:296-309.

31 Glantz SA, Parmley WW. Passive smoking and heart disease: mechanisms and risk. $\mathcal{F} A M A$ 1995;73:1047-53.

32 Kaiserman MJ. The cost of smoking in Canada, 1991. Chronic Dis Can 1991;18:13-19.

33 Single E, Robson L, Xie X, et al. The economic costs of alcohol, tobacco and illicit drugs in Canada, 1992. Addiction 1992;93:991-1006.

34 Forbes SF, Thompson ME. Estimating the health care costs of smokers. Can F Public Health 1983;74:183-90.

35 Chapman S, Leng WW. Tobacco control in the Third World: a resource atlas. Penang, Malaysia: International Organization of Consumers Unions, 1990

36 Jin SG, Lu BY, Yan DY, et al. An evaluation on smoking-induced health costs in China (1988-1989). Biomed Environ Sci 1995;8:342-9.

37 Chen J, Cao JW, Chen Y, et al. Evaluation of medical cost lost due to smoking in Chinese cities. Biomed Environ Sci 1995;8:335-41.

38 Liu BQ, Peto R, Chen ZM, et al. Emerging tobacco hazards in China: 1. Retrospective proportional mortality study of one million deaths. BMF 1998;317:1411-22.

39 Barendregt JJ, Bonneu L, Van Der Mass PJ. The health care costs of smoking. N Engl f Med 1997;337:1052-7.

40 Hodgson TA. The health care costs of smoking. $N$ Engl $\mathcal{F}$ Med 1998;338:470.

41 Tollison RD. Testimony. Tax treatment of organizations providing health care services, and excise taxes on tobacco, guns and ammunition. Hearing before the Committee on Finance, United States Senate, 103rd Congress, 2nd session, 28 Apr 28, 1994:36-41.

42 Abt CC. The social costs of cancer. Social Indicators Research 1975;2:175-90. 